Article

\title{
Elucidation of Transport Mechanism of Paeoniflorin and the Influence of Ligustilide, Senkyunolide I and Senkyunolide A on Paeoniflorin Transport through Mdck-Mdr1 Cells as Blood-Brain Barrier in Vitro Model
}

\author{
Peng-Yi Hu ${ }^{1,2}$, Dan Liu ${ }^{2}$, Qin Zheng ${ }^{2, *}$, Qing Wu ${ }^{1, *}$, Yu Tang ${ }^{2}$ and Ming Yang ${ }^{2}$ \\ 1 School of Chinese Materia Medica, Beijing University of Chinese Medicine, Beijing 100102, China; \\ hpy820515@126.com \\ 2 Key Laboratory of Modern Preparation of Traditional Chinese Medicine, Ministry of Education, \\ Jiangxi University of Traditional Chinese Medicine, Nanchang 330004, China; 18070142107@163.com (D.L.); \\ ty505783@163.com (Y.T.); yangming16@126.com (M.Y.) \\ * Correspondence: zhengqin912006@163.com (Q.Z.); qwu@vip.sina.com (Q.W.); Tel.: +86-10-8473-8603 (Q.Z.); \\ Fax: +86-10-8473-8609 (Q.Z.); Tel./Fax: +86-791-8711-8658 (Q.W.)
}

Academic Editor: Derek J. McPhee

Received: 11 January 2016 ; Accepted: 25 February 2016 ; Published: 2 March 2016

\begin{abstract}
The objectives of the present investigation were to: (1) elucidate the transport mechanism of paeoniflorin (PF) across MDCK-MDR1 monolayers; and (2) evaluate the effect of ligustilide (LIG), senkyunolide I (SENI) and senkyunolide A (SENA) on the transport of PF through blood-brain barrier so as to explore the enhancement mechanism. Transport studies of PF were performed in both directions, from apical to basolateral side $(\mathrm{A} \rightarrow \mathrm{B})$ and from basolateral to apical sides $(\mathrm{B} \rightarrow \mathrm{A})$. Drug concentrations were analyzed by LC-MS/MS. PF showed relatively poor absorption in MDCK-MDR1 cells, apparent permeability coefficients (Papp) ranging from $0.587 \times 10^{-6}$ to $0.705 \times 10^{-6} \mathrm{~cm} / \mathrm{s}$. In vitro experiments showed that the transport of $\mathrm{PF}$ in both directions was concentration dependent and not saturable. The $\mathrm{B} \rightarrow \mathrm{A} / \mathrm{A} \rightarrow \mathrm{B}$ permeability $E R$ of $\mathrm{PF}$ was more than 2 in the MDCK-MDR1 cells, which indicated that the transport mechanism of PF might be passive diffusion as the dominating process with the active transportation mediated mechanism involved. The increased Papp of PF in $\mathrm{A} \rightarrow \mathrm{B}$ direction by EDTA-Na $\mathrm{N}_{2}$ suggested that $\mathrm{PF}$ was absorbed via the paracellular route. The P-gp inhibitor verapamil could significantly increase the transport of $\mathrm{PF}$ in $\mathrm{A} \rightarrow \mathrm{B}$ direction, and $E R$ decreased from 2.210 to 0.690 , which indicated that PF was P-gp substance. The transport of PF in $\mathrm{A} \rightarrow \mathrm{B}$ direction significantly increased when co-administrated with increasing concentrations of LIG, SENI and SENA. An increased cellular accumulation of Rho 123 and Western blot analysis indicated that LIG, SENI and SENA had increased the transport of PF in the BBB models attribute to down-regulate P-gp expression. A decrease in transepithelial electrical resistance (TEER) during the permeation experiment can be explained by the modulation and opening of the tight junctions caused by the permeation enhancer LIG, SENI and SENA.
\end{abstract}

Keywords: paeoniflorin; ligustilide; senkyunolide I; senkyunolide A; blood-brain barrier; P-gp

\section{Introduction}

Paeoniflorin (PF, Figure 1(1)), a monoterpene glycoside, is one of the principal bioactive components extracted from the root of Paeonia lactiflora pall that has been used in Traditional Chinese Medicine for thousands of years [1,2]. Recently, the effect PF has on the nervous system has attracted more attention. PF can ameliorate the decline of memory and learning capacity, protect the cerebral 
ischemia injury, have effects on the treatment of Alzheimer's disease, relieve pain and improve neural synapse plasticity [3-5]. PF is a highly water-soluble phenolic glucoside with poor liposolubility [6,7], and does not easily pass through the blood-brain barrier (BBB). Therefore, enhancing the delivery of $\mathrm{PF}$ to the brain could improve therapeutic efficacy.
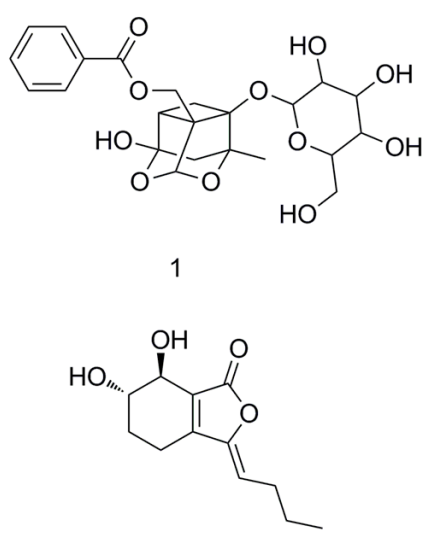

3
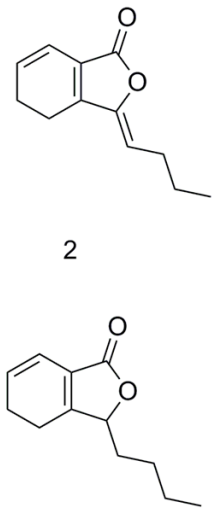

4

Figure 1. Chemical structure of paeoniflorin (1), ligustilide (2), senkyunolide I (3) and senkyunolide A (4).

In many prescriptions of Traditional Chinese Medicine (TCM), certain TCM, called messenger drugs, are considered capable of introducing the main effective drugs in the prescription to the target site to increase therapeutic efficacy. Chuanxiong (Ligusticum chuanxiong Hort.) is one such messenger drug, which is frequently used in the treatment of encephalopathy [8]. Our previous research and some reports have shown that it could enhance drug absorption through gastrointestinal tract [9], and increase the distribution of drugs in brain tissue [10-12]. The combination of chuanxiong and PF is always used to treat CNS diseases. Traditional Chinese herbal formula Danggui Shaoyao San, which contains Paeonia lactiflora Pall., Ligusticum chuanxiong Hort., Angelica sinensis (Oliv.) Diels., Poria cocos (Schw.) Wolf, Alisma orientale (Sam.) Juzep. and Atractylodes macrocephala Koidz., has been used to treat ischemic stroke and Alzheimer's diseases $[13,14]$. PF was one of the main active components in Danggui-Shaoyao-San. Another Traditional Chinese herbal formula Buyang Huanwu decoction, which has been commonly used for the treatment of stroke, also contains chuanxiong and PF [15]. Buyang Huanwu decoction containing chuanxiong has a better therapeutic effecton cerebral is chemia than Buyang Huanwu decoction without chuanxiong, which further confirmed that chuanxiong was a messenger drug. However, the promoting ingredients in chuanxiong and the mechanism are not yet known.

Chuanxiong contains phenolic acids, lactones, alkaloids, volatile oil and other ingredients [16]. Volatile oil of chuanxiong could enhance drug permeation through skin [17], promote the survival of cerebral cortex neurons in vitro, and alleviate the damages caused by ischemia reperfusion [18]. Ligustilide (Figure 1(2), LIG), Senkyunolide I (Figure 1(3), SENI) and Senkyunolide A (Figure 1(4), SENA), phthalide compounds in volatile oil, have various pharmacological effects closely associated with chuanxiong [19-21] and could be absorbed into rat brain tissues through BBB [22]. In this article, LIG, SENI and SENA were regarded as promoting ingredients of chuanxiong to study the underlying mechanisms.

P-glycoprotein (P-gp), encoded by the ABCB1 gene, belongs to the ATP-binding cassette superfamily and is constitutively expressed at the luminal membrane of the brain endothelial cells [23]. The biological function of P-gp is to protect brain from toxic xenobiotics by the energy-dependent efflux of substrates. However, it causes the intracellular concentrations of drugs to decrease and may result in treatment failure. Thus, compounds that inhibit P-gp activities may have the potential to 
improve the clinical outcomes of drugs [24]. Until now, it was unclear whether LIG, SENA and SENI could inhibit P-gp activities to influence the transport of PF through BBB.

MDR1-transfected Madin-Darby canine kidney (MDCK-MDR1) cell, which is human P-gp-overexpressing, has some properties similar to the BBB. MDCK-MDR1 cell displays morphological enzymatic and antigenic cell markers, which are also found in cerebral endothelial cells, and have been reported as a suitable model in vitro for BBB $[25,26]$. MDCK-MDR1 cell was considered to be one of promising cells to determine the potential distribution of drugs in brain and the transport mechanism of drugs that passed the BBB $[27,28]$. The present study was undertaken to explore the transport mechanism of PF using MDCK-MDR1 cells modes in vitro, to evaluate the influence of LIG, SENI and SENA on the transport of PF, and to analyze the mechanism of the interactions.

\section{Results}

The cytotoxicity of PF was evaluated in MDCK-MDR1 cells with the aid of the MTT assay, and the results are shown in Figure 2. PF group has no cell cytotoxicity in the concentration range of $0-800 \mu \mathrm{g} / \mathrm{mL}$. Therefore, we used concentrations within this range for subsequent experiments. LIG, SENA and SENI groups have no cell cytotoxicity in the concentration range of 0-120 $\mu \mathrm{g} / \mathrm{mL}$. The mixture of $400 \mu \mathrm{g} / \mathrm{mL}$ PF combined with three ingredients of chuanxiong $(w / w)$ have no cell cytotoxicity in the concentration range of $0-80 \mu \mathrm{g} / \mathrm{mL}$ calculated with LIG, SENI, and SENA.

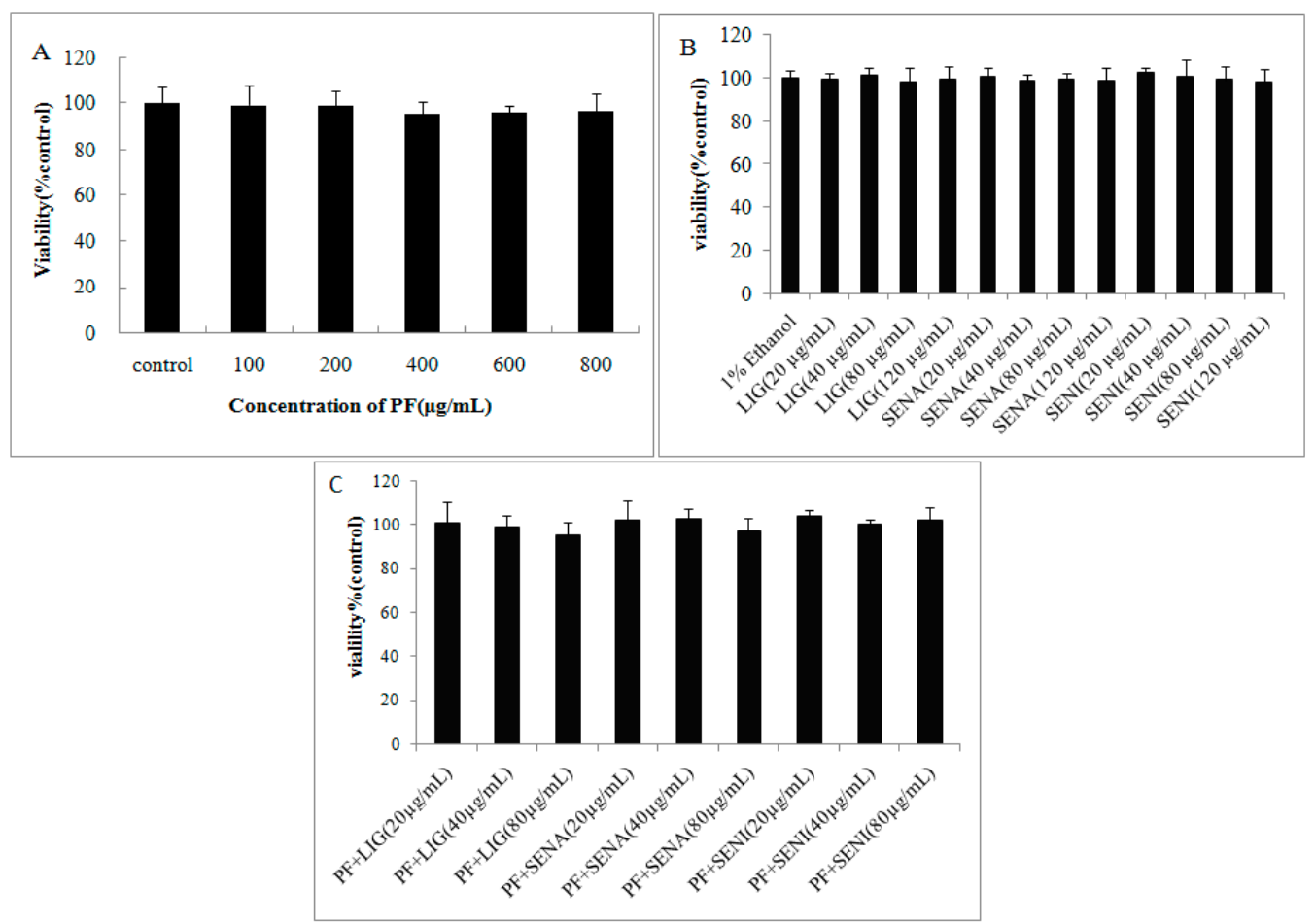

Figure 2. Cytotoxicity of paeoniflorin (PF) and its combination determined by 3-(4,5-dimethylthiazol2-yl)-2,5-diphenyltetrazolium bromide (MTT) test on MDCK-MDR1 cells: (A) cytotoxicity of PF; (B) cytotoxicity of LIG, SENI and SENA; and (C) cytotoxicity of $400 \mu \mathrm{g} / \mathrm{mL}$ PF combined with LIG, SENI and SENA. Date are expressed as mean \pm standard deviation $(\mathrm{SD})(n=6)$.

Various concentrations of PF transports were tested across MDCK-MDR1 (Table 1). In general, drugs with high Papp $\left(>1 \times 10^{-5} \mathrm{~cm} / \mathrm{s}\right)$ can be well-absorbed, while those with low Papp $\left(<1 \times 10^{-6} \mathrm{~cm} / \mathrm{s}\right)$ are poorly absorbed [29]. The Papp $(\mathrm{A} \rightarrow \mathrm{B})$ of PF between 0.587 and $0.705 \times 10^{-6} \mathrm{~cm} / \mathrm{s}$ in MDCK-MDR1 cells showed that it is relatively poorly absorbed. The Papp of PF in $\mathrm{A} \rightarrow \mathrm{B}$ direction did not differ significantly (Table 1 ), and the fluxes of PF were linearly associated with the concentration (Figure 3), which indicated that the transport of PF was concentration dependent, 
not saturable and mainly passive transport. The linear equation from apical side to basolateral side was $\mathrm{y}=0.007 \mathrm{x}-0.117(r=0.9945, n=3)$, and the linear equation from basolateral side to apical side was $\mathrm{y}=0.014 \mathrm{x}+0.022(r=0.9975, n=3)$, where $\mathrm{y}$ is the flux of PF and $\mathrm{x}$ is the concentration of PF. The $\mathrm{B} \rightarrow \mathrm{A} / \mathrm{A} \rightarrow \mathrm{B}$ permeability ER of PF was more than 2 in the MDCK-MDR1 cells, which indicated that the transport mechanism of PF might be passive diffusion as the dominating process with the active transportation mediated mechanism involved.

Table 1. Increasing concentration of PF transport across MDCK-MDR1 cell monolayers.

\begin{tabular}{cccc}
\hline Concentration of PF $(\mu \mathrm{g} / \mathbf{m L})$ & Papp $(\mathbf{A} \rightarrow \mathbf{B})\left(\times \mathbf{1 0}^{-6} \mathbf{c m} / \mathbf{s}\right)$ & Papp $(\mathbf{B} \rightarrow \mathbf{A})\left(\times \mathbf{1 0}^{-6} \mathbf{c m} / \mathbf{s}\right)$ & ER $(\mathbf{B} \rightarrow \mathbf{A} / \mathbf{A} \rightarrow \mathbf{B})$ \\
\hline 100 & $0.697 \pm 0.053$ & $1.549 \pm 0.092$ & 2.222 \\
200 & $0.691 \pm 0.082$ & $1.475 \pm 0.363$ & 2.134 \\
400 & $0.587 \pm 0.088$ & $1.297 \pm 0.084$ & 2.210 \\
600 & $0.666 \pm 0.072$ & $1.436 \pm 0.201$ & 2.156 \\
800 & $0.705 \pm 0.107$ & $1.418 \pm 0.097$ & 2.011 \\
\hline
\end{tabular}

Papp, permeability; A, apical side; B, basolateral side. Values are mean $\pm \mathrm{SD}(n=3)$.

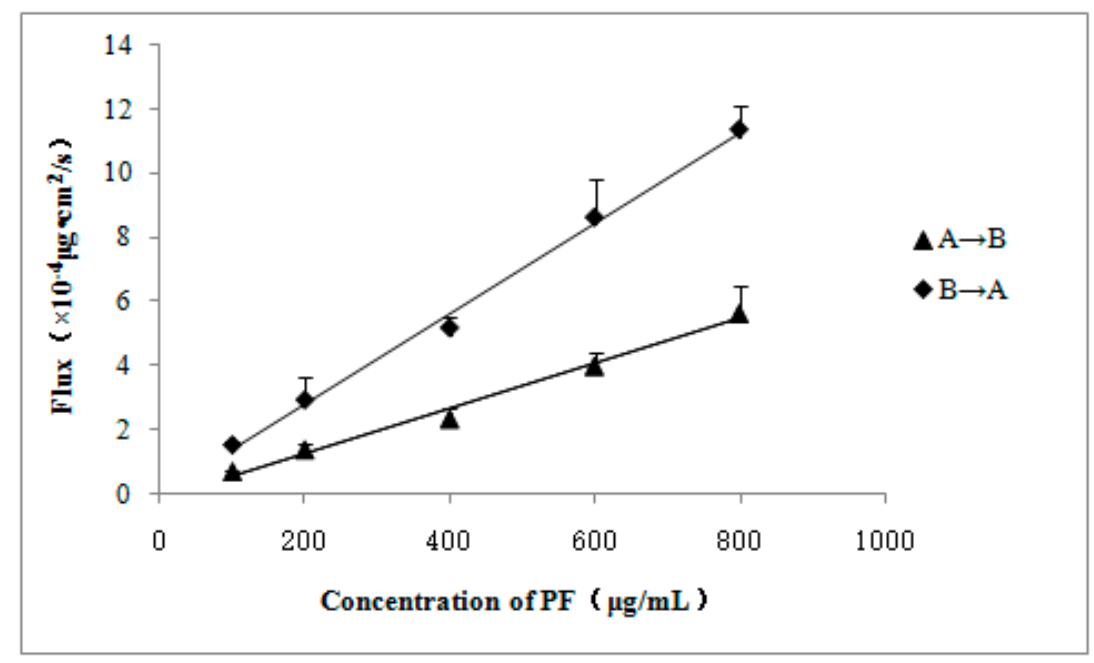

Figure 3. The Flux of PF transport across MDCK-MDR1 cell monolayers. A, apical side; B, basolateral side. Values are mean $\pm \mathrm{SD}(n=3)$.

To determine the potential role of P-gp in the transport of PF, a P-gp inhibitor, verapamil (VER), was added to medium that contained $400 \mu \mathrm{g} / \mathrm{mL}$ PF (Table 2). The Papp $(\mathrm{A} \rightarrow \mathrm{B})$ of PF increased up to about 1.2-fold in comparison with the non-verapamil added (from 0.587 to $0.707 \times 10^{-6} \mathrm{~cm} / \mathrm{s}$ ). In the presence of P-gp inhibitor, the $\mathrm{B} \rightarrow \mathrm{A} / \mathrm{A} \rightarrow \mathrm{B}$ permeability ER of PF was 0.690, which suggested that PF was P-gp substance [30].

Table 2. The effect of P-gp inhibitors on transport of PF in MDCK-MDR1 cell monolayer.

\begin{tabular}{cccc}
\hline Group & Papp $(\mathbf{A} \rightarrow \mathbf{B})\left(\times \mathbf{1 0}^{-6} \mathbf{c m} / \mathbf{s}\right)$ & Papp $(\mathbf{B} \rightarrow \mathbf{A})\left(\times \mathbf{1 0}^{-6} \mathbf{c m} / \mathbf{s}\right)$ & ER $(\mathbf{B} \rightarrow \mathbf{A} / \mathbf{A} \rightarrow \mathbf{B})$ \\
\hline $400 \mu \mathrm{g} / \mathrm{mL} \mathrm{PF}$ & $0.587 \pm 0.088$ & $1.297 \pm 0.084$ & 2.210 \\
$400 \mu \mathrm{g} / \mathrm{mL} \mathrm{PF}+100 \mathrm{mmol} / \mathrm{L}$ verapamil & $0.707 \pm 0.062^{*}$ & $0.488 \pm 0.093^{\#}$ & 0.690 \\
\hline
\end{tabular}

Papp, permeability; A, apical side; B, basolateral side. Values are mean $\pm \mathrm{SD}(n=3)$. Differs from PF $(400 \mu \mathrm{g} / \mathrm{mL}):^{*} p<0.05,{ }^{\#} p<0.01$.

Although the surface area is much larger for the transcellular route, the paracellular route is the preferred absorption pathway for many water-soluble and poorly lipid-soluble drugs, ionized drugs, and high molecular weight compounds. EDTA-Na $\mathrm{Na}_{2}$ could destroy the intercellular structure that is 
named tight junction of the endotheliocyte and increase the paracellular permeation of hydrophilic macromolecules [31,32]. If the transport mechanism of a drug involves paracellular diffusion, its transport would improve when the tight junction structure is opened or destroyed. Thus, in this study, we investigated the transport of PF in the absence or presence of EDTA-Na 2 (Table 3). The permeability of PF significantly increased when $2.5 \mathrm{mmol} / \mathrm{L}$ EDTA-Na 2 was added $(p<0.01)$. The Papp $(\mathrm{A} \rightarrow \mathrm{B})$ of PF increased up to about five-fold in comparison with the non- EDTA-Na $a_{2}$ added (from 0.587 to $\left.2.736 \times 10^{-6} \mathrm{~cm} / \mathrm{s}\right)$. It suggested that PF was absorbed via the paracellular route. These results indicated that PF transported across the MDCK-MDR1 cell monolayers by both paracellular and transcellular diffusion.

Table 3. The effect of EDTA-Na 2 on transport of PF in MDCK-MDR1 cell monolayer.

\begin{tabular}{cc}
\hline Group & Papp $(\mathbf{A} \rightarrow \mathbf{B})\left(\times \mathbf{1 0}^{-6} \mathbf{c m} / \mathbf{s}\right)$ \\
\hline $400 \mu \mathrm{g} / \mathrm{mL} \mathrm{PF}$ & $0.587 \pm 0.088$ \\
$400 \mu \mathrm{g} / \mathrm{mL} \mathrm{PF}+2.5 \mathrm{mmol} /$ LEDTA-Na 2 & $2.736 \pm 0.212^{\#}$ \\
\hline
\end{tabular}

Papp, permeability; A, apical side; B, basolateral side. Values are mean \pm SD $(n=3)$. Differs from PF $(400 \mu \mathrm{g} / \mathrm{mL}):{ }^{\#} p<0.01$.

The drug-drug interaction experiment of PF transport was carried out in MDCK-MDR1 cells to investigate the effect of bioactive ingredients of chuanxiong on its permeability. The changed transports of PF, caused by various concentrations of LIG, SENA and SENI, are shown in Figure 4. Results showed that transports of PF continuously increased in $\mathrm{A} \rightarrow \mathrm{B}$ direction with rising concentration of LIG, SENI and SENA. In the presence of LIG $(40$ and $80 \mu \mathrm{g} / \mathrm{mL})$, the $\mathrm{A} \rightarrow \mathrm{B}$ fluxes of PF in MDCK-MDR1 were significantly increased ( $p<0.01$ and $p<0.05$, respectively); in the presence of SENI or SENA $(20,40$, and $80 \mu \mathrm{g} / \mathrm{mL})$, the Papp $(\mathrm{A} \rightarrow \mathrm{B})$ of PF in MDCK-MDR1 were significantly increased $(p<0.05, p<0.01$, and $p<0.01$, respectively); and $80 \mu \mathrm{g} / \mathrm{mL}$ of SENA has the strongest promoting effect, for it significantly increased by approximately 109\% the transport of PF in MDCK-MDR1 cell.

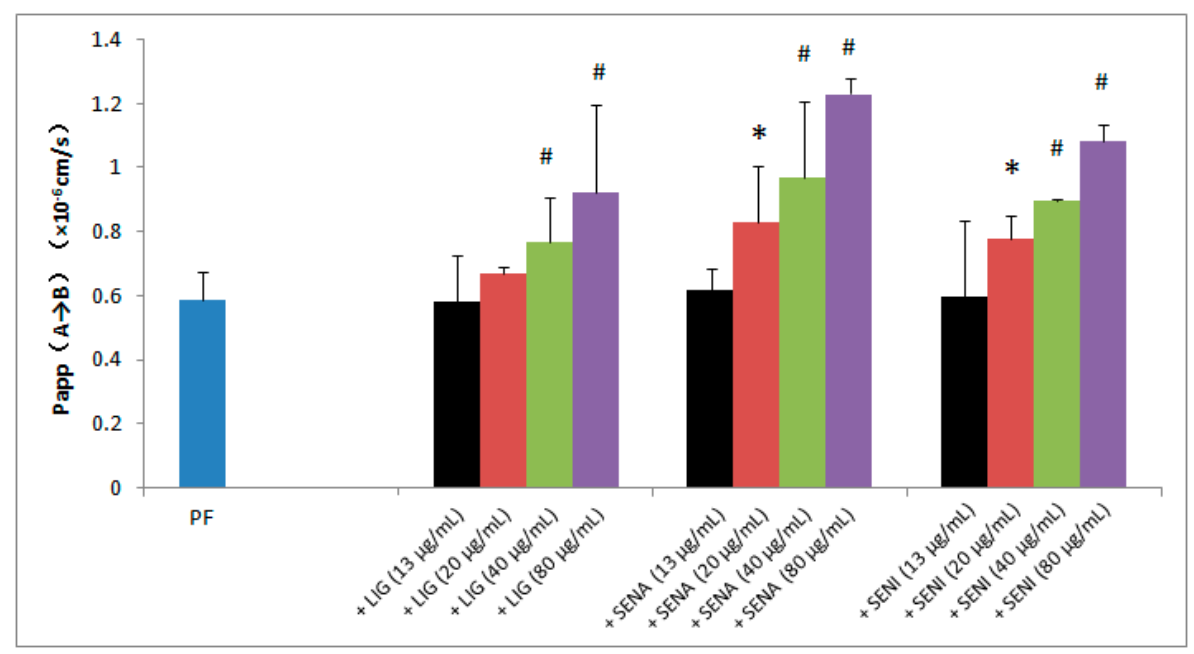

Figure 4. Effects of LIG, SENA and SENI on the transport of PF in MDCK-MDR1 cells. Papp, permeability; A, apical side; $\mathrm{B}$, basolateral side. Values are mean $\pm \mathrm{SD}(n=3)$. Differs from PF $(400 \mu \mathrm{g} / \mathrm{mL}){ }^{*} p<0.05,{ }^{*} p<0.01$.

Comparisons of the transepithelial electrical resistance (TEER) of the cell monolayer in the absence or presence of the three bioactive ingredients of chuanxiong are shown in Figure 5. TEER of cells treated with LIG $(20 \mu \mathrm{g} / \mathrm{mL})$ and SENA $(80 \mu \mathrm{g} / \mathrm{mL})$ significantly decreased during permeation studies $(p<0.01)$. TEER of cells treated with LIG $(80$ and $40 \mu \mathrm{g} / \mathrm{mL})$, SENA $(40$ and $20 \mu \mathrm{g} / \mathrm{mL})$ and SENI $(80 \mu \mathrm{g} / \mathrm{mL})$ markedly decreased during permeation studies $(p<0.05)$. A decrease in TEER during 
the permeation experiment can be explained by the modulation and opening of the tight junctions caused by the permeation enhancer LIG, SENI and SENA, but further research should be carried out to verify this.

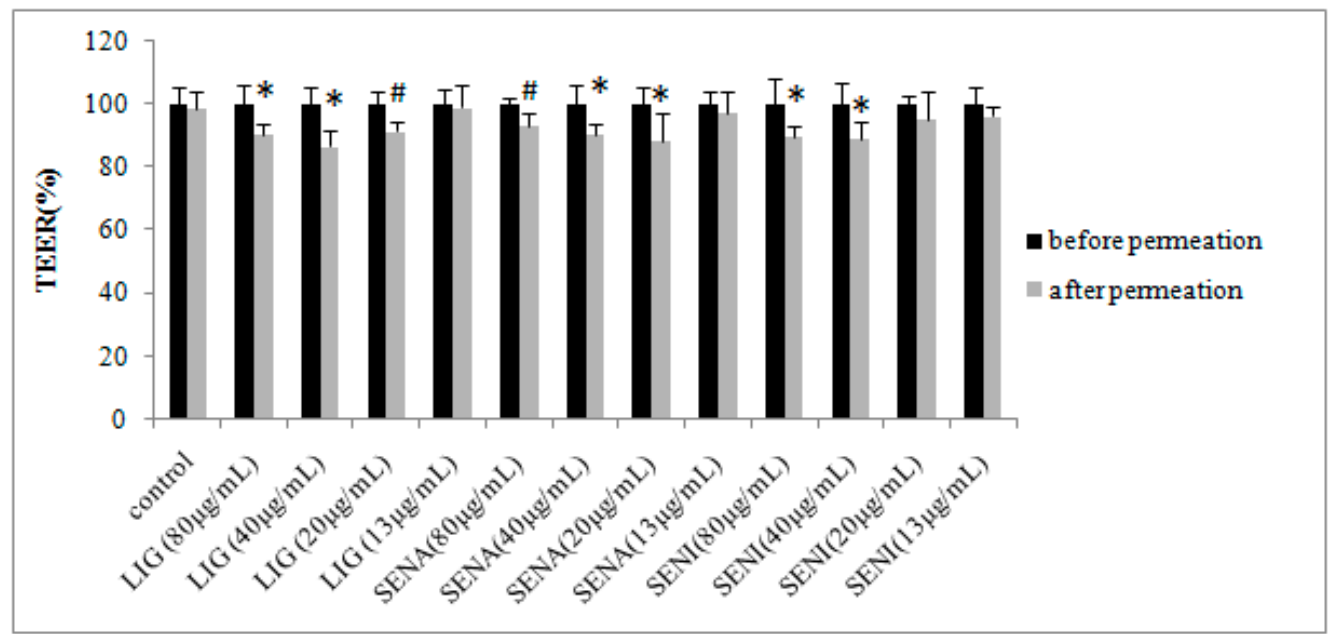

Figure 5. Transepithelial electrical resistance (TEER) before and after permeation of $400 \mu \mathrm{g} / \mathrm{mL}$ PF as control and in the presence of $400 \mu \mathrm{g} / \mathrm{mL}$ PF combined with LIG, SENI and SENA across MDCK-MDR1 monolayers. Data are expressed as mean $\pm \mathrm{SD}(n=3)$. ${ }^{*} p<0.05$ and ${ }^{\#} p<0.01$ compared with the value before permeation.

Rhodamine 123 (Rho 123) is a fluorescent dye that can be removed from the cells by P-gp function. Therefore, an increased cellular accumulation of Rho 123 is generally considered a marker of diminished P-gp efflux function [33]. The effects of different ingredients on P-gp-mediated efflux function in MDCK-MDR1 are shown in Figure 6. Verapamil, as P-gp inhibitor, significantly enhanced the intake of Rho 123 ( $p<0.01)$. LIG, SENA and SENI could increase the intake of Rho 123 in a dose-dependent manner (Figure 5). Compared with control group, $80 \mu \mathrm{g} / \mathrm{mL}$ of SENA significantly increased by approximately 87\% intake of Rho $123(p<0.01)$, while $80 \mu \mathrm{g} / \mathrm{mL}$ of LIG and SENI markedly increased by approximately $35 \%(p<0.05)$. While $40 \mu \mathrm{g} / \mathrm{mL}$ of LIG, SENI and SENA increased by approximately $15 \%$ intake of Rho 123 when compared with control group, there was no significant difference $(p>0.05)$. These data suggested that LIG, SENI and SENA could down-regulate P-gp efflux function to enhance the transport of P-gp substrates, PF across BBB.

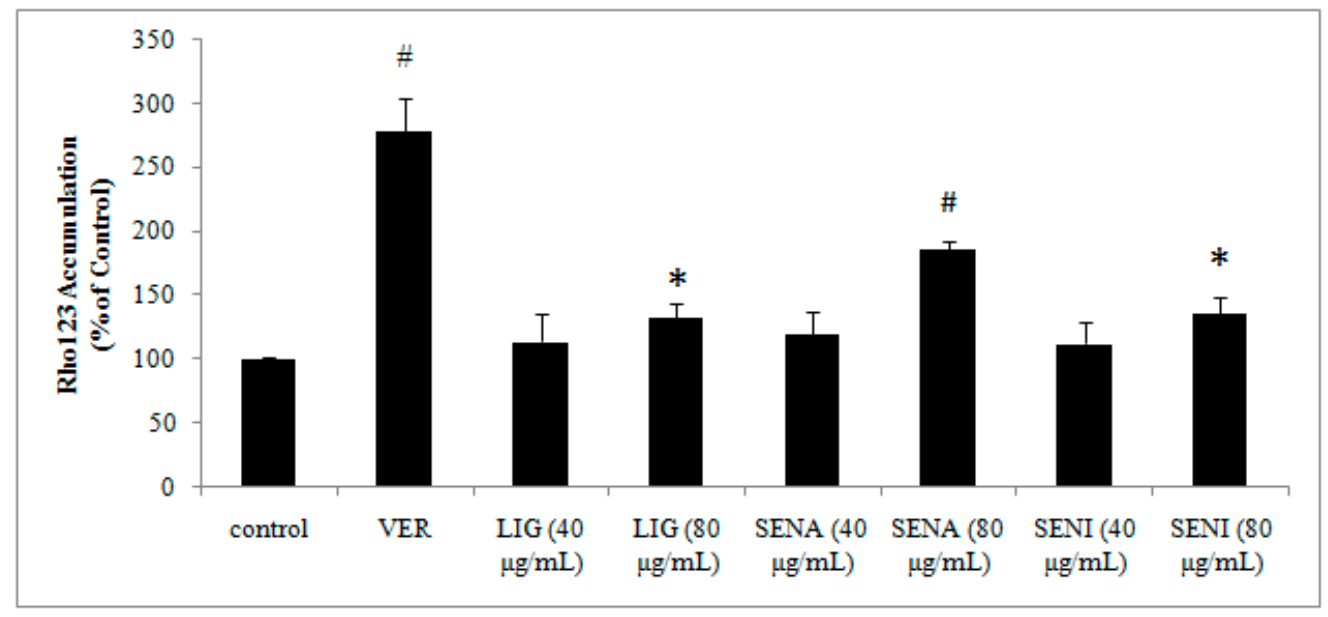

Figure 6. Effects of Ver, LIG, SENA and SENI on P-gp-mediated efflux function in MDCK-MDR1. Values are mean $\pm \mathrm{SD}(n=3)$. Differs from control group: ${ }^{*} p<0.05,{ }^{*} p<0.01$. 
Western blot was used to investigate the effect of LIG, SENA and SENI on the expression of P-gp in MDCK-MDR1 cells. The results revealed a band of $170 \mathrm{kDa}$, corresponding to P-gp (Figure 7A). It was found that P-gp expressions in MDCK-MDR1 cells were markedly down-regulated by LIG, SENA and SENI. In Figure 7B, P-gp expressions of cells treated with LIG $(20 \mu \mathrm{g} / \mathrm{mL})$ and SENA $(20 \mu \mathrm{g} / \mathrm{mL})$ significantly down-regulated $(p<0.05)$. P-gp expressions of cells treated with LIG $(40,80 \mu \mathrm{m} / \mathrm{mL})$, SENA $(40,80 \mu \mathrm{g} / \mathrm{mL})$ and SENI $(20,40,80 \mu \mathrm{g} / \mathrm{mL})$ markedly down-regulated $(p<0.01)$. These data suggested that the enhanced transports of PF can be explained by the reduced expression of P-gp in MDCK-MDR1 cells caused by LIG, SENA and SENI.

A

\section{P-gp}
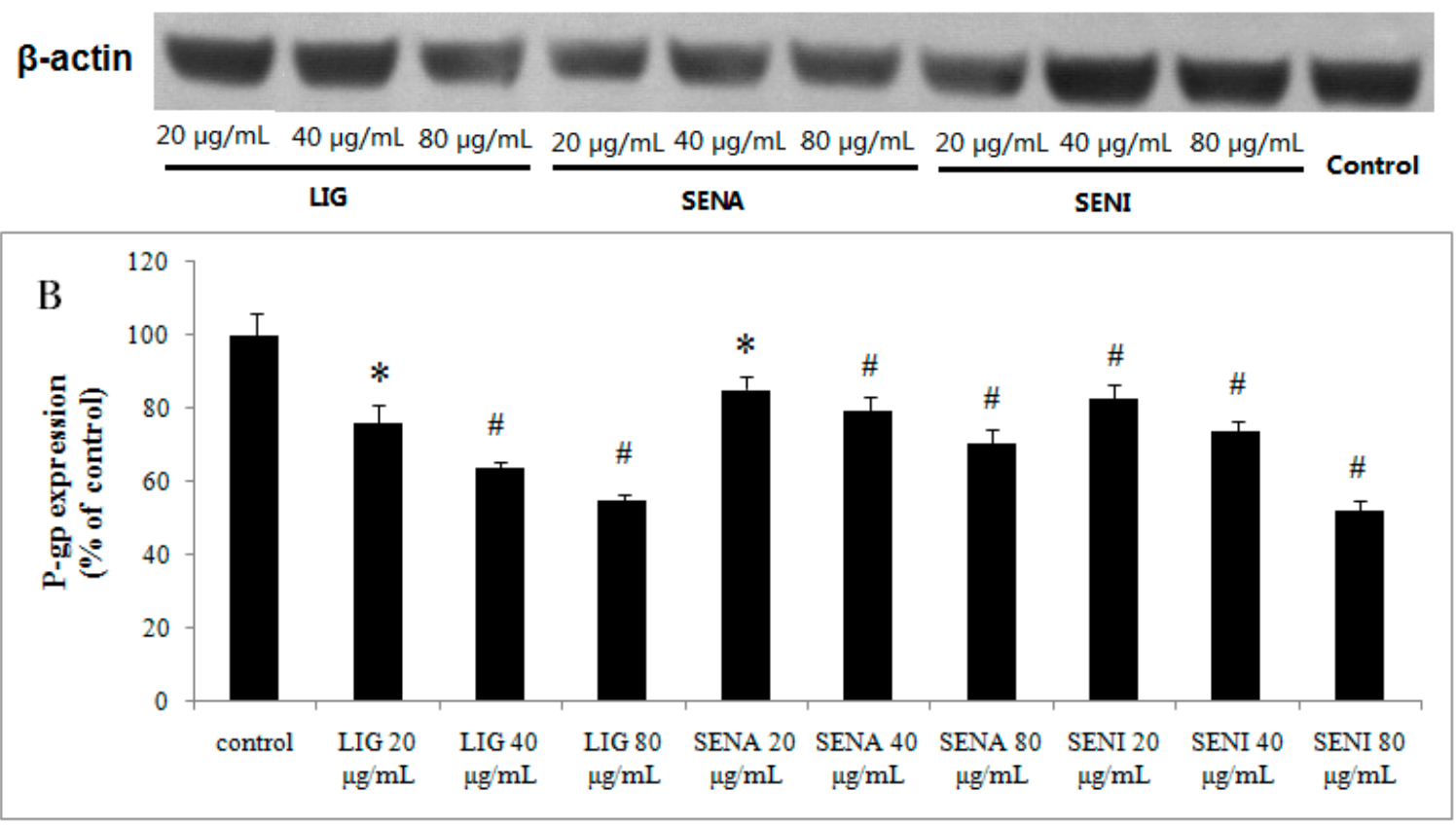

Figure 7. Effects of LIG, SENA and SENI on P-gp expression in MDCK-MDR1 cells: (A) representative P-gp expression by Western blot on MDCK-MDR1 treated with different concentration of LIG, SENA and SENI; and (B) quantitative data of P-gp expression. Values are mean $\pm \mathrm{SD}(n=3)$. Differs from control group: ${ }^{*} p<0.05,{ }^{*} p<0.01$.

Libdock (Discovery studio version 4.0) is commercial software for docking the ligands into active site of the protein. It calculates the hotspot map for the protein active site, which includes polar and apolar groups. This hotspot map is further used to align the ligands to form favorable interactions. Finally, it minimizes all the ligand poses and based on the ligands score they are ranked [34-36]. The docking analysis in Table 4 revealed the interaction of ligands-P-gp with the deep pocket of the identified binding site. The involved interactions between the small molecule and the pocket residues are numerous. Verapamil and PF with the highest LibDock Score indicated that they are P-gp substrate, which was consistent with the results in this experiment. Verapamil enhanced the transport of PF in MDCK-MDR1, and the mechanism was that verapamil could competitively bind with P-gp. LIG, SENA and SENI with lower LibDock Score can be explained by that they enhanced the transport of PF by inhibiting the expression of P-gp not by competitively binding with P-gp. 
Table 4. The detailed binding modes of ligands with P-gp and the LibDock Socre.

\begin{tabular}{ccccc}
\hline NO & English Name & The Type of Interaction & The Key Amino Acids & LibDock Score \\
\hline 1 & PF & $\begin{array}{c}\text { hydrogen-bonding interaction } \\
\text { hydrophobic interaction }\end{array}$ & $\begin{array}{c}\text { gln721 and ser 725 } \\
\text { val978, leu971, and phe724 }\end{array}$ & 139 \\
\hline 2 & LIG & $\begin{array}{c}\text { hydrogen-bonding interaction } \\
\text { hydrophobic interaction }\end{array}$ & $\begin{array}{c}\text { ser 975 } \\
\text { phe974, phe332, phe724, val978, and phe728 }\end{array}$ & 86 \\
\hline 3 & SENI & $\begin{array}{c}\text { hydrogen-bonding interaction } \\
\text { hydrophobic interaction }\end{array}$ & leu971, phe728, phe332, phe724, and val978 & 91 \\
\hline 4 & SENA & $\begin{array}{c}\text { hydrogen-bonding interaction } \\
\text { hydrophobic interaction }\end{array}$ & phe71, phe974, phe332, phe728, val978 & 89 \\
\hline 5 & Verapamil & $\begin{array}{c}\text { hydrogen-bonding interaction } \\
\text { hydrophobic interaction }\end{array}$ & $\begin{array}{c}\text { gln721 } \\
\text { tyr303, tyr306, leu335, phe332, } \\
\text { phe724, met 982, val978, and phe728 }\end{array}$ & 138 \\
\hline
\end{tabular}

\section{Materials and Methods}

\subsection{Materials}

Polyester (PET) cell culture inserts and 12-well plates (12 mm diameter, $0.4 \mu \mathrm{m}$ pore size) were purchased from Corning Costar Corporation (Cambridge, MA, USA). PF and verapamil were obtained from the National Institute for the Control of Pharmaceutical and Biological Products (Beijing, China). LIG, SENI and SENA were purchased from Chengdu Herbpurify Co., Ltd. (Chendu, China). Rhodamine 123 was purchased from Nanjing KeyGEN BioTeCH Co., Ltd. (Nanjing, China). Acetonitrile (Mreda Inc., Merck, Darmstadt, Germany) was of HPLC grade.

\subsection{Cell Culture}

MDCK-MDR1 cells were purchased fromCinoAsia co., Ltd. (Shanghai, China). Cells were cultured in Dulbecco's modified Eagle's media (DMEM, containing L-glutamineand 25 mM HEPES), supplemented with $10 \%$ heat-inactivated fetal bovine serum (FBS) as well as $100 \mathrm{U} / \mathrm{mL}$ penicillin and $100 \mu \mathrm{g} / \mathrm{mL}$ streptomycin. All cell lines were maintained at $37^{\circ} \mathrm{C}$ with $5 \% \mathrm{CO}_{2}$. The cells were seeded at a density of 250,000 cells $/ \mathrm{cm}^{2}$, and were grown to confluence on PET inserts and maintained for seven days before the experiment. Fresh media were replaced to the cells every other day after seeding and $24 \mathrm{~h}$ before the transport study.

\subsection{Cytotoxicity Assays}

The capacity of PF, LIG, SENI and SENA to interfere with the growth of MDCK-MDR1 cells wa determined with the aid of the 3-(4,5-dimethylthiazol-2-yl)-2,5-diphenyltetrazolium bromide (MTT) dye assay. LIG, SENI and SENA were dissolved and diluted by HBSS containing 1\% ethanol. Cells were seeded in 96 microtiter plates with flat-bottomed wells in a total volume of $200 \mu \mathrm{L}$ of culture medium at a density of $1 \times 10^{5}$ cells $/ \mathrm{mL}$. Plates were then incubated at $37^{\circ} \mathrm{C}$ in a $5 \% \mathrm{CO}_{2}$ atmosphere. After $24 \mathrm{~h}$, the medium was removed and replaced with a fresh medium containing increasing concentrations of the compounds. After incubation for $24 \mathrm{~h}, 20 \mu \mathrm{L}$ of a $5 \mathrm{mg} / \mathrm{mL}$ MTT solution in culture medium was added to each well and the mixtures were incubated at $37^{\circ} \mathrm{C}$ until blue deposits were visible. The assay measures the amount of MTT reduction brought about by mitochondrial dehydrogenase and assumes that cell viability (corresponding to the reductive activity) is proportional to the production of purple formazan, which is measured spectrophotometrically. The colored metabolite was then dissolved in DMSO. Absorbance was measured at $490 \mathrm{~nm}$ with a Multiskan Go microplate reader (BioTek, Winooski, VT, USA). Wells with drugs and cells was used as sample group, and the absorption was recorded as $\mathrm{A}_{\text {sample. }}$. Wells with the same concentration of drugs but without seeded cells were

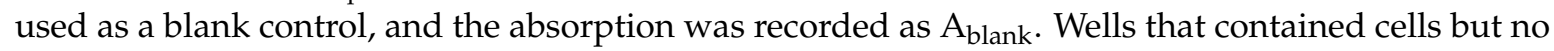
sample solution were used as negative control, the absorption was recorded as $\mathrm{A}_{\text {control }}$. The mean 
absorbance of six measurements for each compound was expressed as a percentage of the absorbance of the untreated control and plotted against complex concentration.

\subsection{Transport Studies Across MDCK-MDR1}

Cell monolayers were pre-incubated in Hank's buffered salt solution (HBSS, pH 7.4) for $30 \mathrm{~min}$ at $37^{\circ} \mathrm{C}$. Transepithelial electrical resistance (TEER) values were measured across the monolayers using a Millipore Millicell ERS system equipped with chopstick electrodes (Millipore Corporation, Billerica, MA, USA). Approximate MDCK-MDR1 values ranged from 500 to $800 \Omega \cdot \mathrm{cm}^{2}$. To measure apical $(\mathrm{A}) \rightarrow$ basolateral (B) transporter, $0.5 \mathrm{~mL}$ of drug solution was added in A side and $1.5 \mathrm{~mL}$ of HBSS in B side. Basolateral (B) $\rightarrow$ apical (A) transporter was evaluated adding $1.5 \mathrm{~mL}$ of drug solution in $\mathrm{B}$ side and $0.5 \mathrm{~mL}$ of HBSS in A side [37]. The final organic solvent concentration in HBSS was always kept below $1 \%$, a concentration, which did not alter cell viability or permeability [38]. PF transport was studied at five concentrations: 100, 200, 400, 600 and $800 \mu \mathrm{g} / \mathrm{mL}$. The effects of LIG, SENA and SENI on PF transport were studied at 13,20, 40 and $80 \mu \mathrm{g} / \mathrm{mL}$ concentrations in the presence of $400 \mu \mathrm{g} / \mathrm{mL}$ PF. The P-gp inhibitor verapamil at $100 \mu \mathrm{mol} / \mathrm{L}$ concentrations was also used to study the changed transport of PF.

Each measurement was evaluated in triplicate. Cells were incubated in a $37^{\circ} \mathrm{C}$ shaking incubator. Two hundred-microliter aliquots were taken from the apical side (to study $\mathrm{B} \rightarrow \mathrm{A}$ transport) and $500 \mu \mathrm{L}$ of aliquots were taken from the basal side (to study $A \rightarrow B$ transport) at 30, 60, 90, 120, and $150 \mathrm{~min}$ time intervals. The same volume of fresh pre-warmed HBSS was added to keep the volume constant. $200 \mu \mathrm{L}$ of PF samples was mixed with $180 \mu \mathrm{L}$ methanol, and then $20 \mu \mathrm{L}$ IS solution at $25.0 \mu \mathrm{g} / \mathrm{mL}$ was added, by vortex agitation for $3 \mathrm{~min}$ and then centrifuged for $10 \mathrm{~min}$ at 16,000 rpm. The supernatants were transferred to autosampler vials and injected into the LC-MS system.

\subsection{LC-MS/MS Measurement of PF.}

An HPLC system consisting of a solvent-delivery system LC-30 AD, an autosampler SIL-30 AC, a column oven CTO-30 AC, a solvent degasser DGU-20A3 and a controller CBM-20A from AB Sciex (Framingham, MA, USA) was used in the study. Separation was conducted using a Phenomenex Kinetex NB-C18 $\left(100 \times 3.0 \mathrm{~mm}, 2.6 \mu \mathrm{m}\right.$, Torrance, CA, USA). The column oven was maintained at $30^{\circ} \mathrm{C}$. The mobile phase was water as mobile phase $\mathrm{A}$ and acetonitrile as mobile phase $\mathrm{B}$. The linear gradient elution program was set according to preliminary tests: $5 \% \mathrm{~B}, 0-0.5 \mathrm{~min} ; 5 \%-20 \% \mathrm{~B}, 0.5-2.0 \mathrm{~min}$; $20 \%-40 \%$ B , 2.0-3.0 min; 40\%-90\% B, 3.0-5.0 min; 90\% B, 5.0-8.0 min; 90-5\% B, 8.0-8.1min; and 5\% B, 8.1-12.0 $\mathrm{min}$, with the flow rate kept at $0.4 \mathrm{~mL} / \mathrm{min}$. The injection volume was set at $5 \mu \mathrm{L}$.

The MS analysis was performed on a 4500 QTRAPTM system from Applied Biosystems (AB Sciex) equipped with Turbo $\mathrm{V}$ sources and Turbo Ionspray ${ }^{\mathrm{TM}}$ interface. Electrospray ionization was performed in negative mode. The mass spectrometric parameters were optimized as: Turbo Ion Spray (TIS) temperature, $650{ }^{\circ} \mathrm{C}$; ion spray voltage, $-4500 \mathrm{~V}$; curtain gas, nitrogen, 30 ; nebulizing gas, 50 ; TIS gas, 50; declustering potential, $-130 \mathrm{eV}$ for $\mathrm{PF}, 0 \mathrm{eV}$ for internal standard (IS, gastrodin); collision energy, $-30 \mathrm{eV}$ for $\mathrm{PF},-35 \mathrm{eV}$ for IS. The precursor-product ion pairs used in multiple reactions monitoring mode were 479.3-120.9 for PF, 285.0-122.8 for IS with dwell times of $100 \mathrm{~ms}$; quadrupoles $\mathrm{Q}_{1}$ and $\mathrm{Q}_{3}$ were set on unit resolution. Analyst Software ${ }^{\mathrm{TM}}$ (version 1.6.1) was used to process the obtained data.

\subsection{Data Analysis and Statistics}

The percentage of cell toxicity in the MTT assay was calculated using the following Equation (1):

$$
\text { Viability }(\%) \frac{A_{\text {sample }}-A_{\text {black }}}{A_{\text {control }}-A_{\text {black }}} \times 100
$$


The apparent permeability coefficients $\left(\mathrm{P}_{\mathrm{app}}\right)$ for PF were calculated according to the following Equation (2), and the flux of PF was calculated according to Equation (3):

$$
\begin{gathered}
P_{\text {app }}=\frac{d Q}{d t \times A \times C_{0}} \\
\text { Flux }=\frac{d Q}{d t \times A}
\end{gathered}
$$

where $\mathrm{dQ} / \mathrm{dt}$ is the cumulative transport rate of the compound on the receiving side $(\mathrm{mM} / \mathrm{s}), \mathrm{A}$ is the surface area of the cell monolayer $\left(\mathrm{cm}^{2}\right)$, and $\mathrm{C}_{0}$ is the initial concentration in the donor compartment $(\mathrm{mM} / \mathrm{cm})$. The efflux ratio (ER) was calculated according to the following Equation (4):

$$
\mathrm{ER}=\frac{\mathrm{Papp}_{\mathrm{BL} \rightarrow \mathrm{AP}}}{\text { Papp }_{\mathrm{AP} \rightarrow \mathrm{BL}}}
$$

Experimentally derived in vitro data were shown as mean \pm standard deviation (SD). Data were analyzed by one-way analysis of variance (ANOVA), followed by LSD test to analyze differences among multiple groups comparatively to control group (SPSS13.0 Statistical software). Significance was set at $p<0.05$.

\subsection{TEER Measurement}

Transepithelial electrical resistance (TEER) of the monolayers was measured with the EVOM instrument (Millipore Corporation). The TEER of untreated cells and cells treated with LIG, SENI and SENA was determined in HBSS before and after the experiment. The measured TEER before the experiment was set as $100 \%$ and all other values were calculated according to this.

\subsection{The Effects of LIG, SENI and SENA on Rhodamine 123 Accumulation}

Rho 123 efflux assay was used to measure the activity of P-gp in MDCK-MDR1 cells according to previous methods [39]. In total, $5 \times 10^{5}$ cells $(1 \mathrm{~mL})$ grown to confluency in a heparinized eppendorf (EP) tube were treated with 20, 40 and $80 \mu \mathrm{g} / \mathrm{mL}$ of LIG, SENI, or SENA, or with $100 \mu \mathrm{mol} / \mathrm{L}$ verapamil, for $1 \mathrm{~h}$, and subsequently incubated in $5 \mu \mathrm{mol} / \mathrm{L}$ rhodamine123 for $1 \mathrm{~h}$. After incubation with rhodamine 123, cells were washed with ice-cold HBSS for three times and solubilized in $0.5 \mathrm{~mL}$ n-butyl alcohol. Fluorescence of rhodamine 123 was measured with emission wavelength at $535 \mathrm{~nm}$ and excitation wavelength at $485 \mathrm{~nm}$ using a fluorescence spectrophotometer (Victor, PerkinElmer, Waltham, MA, USA). Each experiment was repeated at least three times to ensure uptake and consistency and reproducibility of the experiments.

\subsection{Western-Blot Analysis}

Cells treated with different concentrations of LIG, SENA and SENI for 8 hours were subject to Western blot assay. Proteins were extracted from whole cell lysates and separated by sodium dodecyl sulfate-polyacrylamide gel electrophoresis, then transferred to a polyvinylidene fluoride (PVDF) membrane. The following primary antibodies were used: rabbit anti-P-gp (1:1000; Abcam, Cambridge, MA, USA) and mouse anti- $\beta$-actin (1:2000; Abcam). Membranes were then incubated with the horseradish peroxidase-conjugated secondary anti-bodies (1:5000; Abcam). The transferred proteins were incubated with enhanced chemiluminescence (ECL) substrate solution and visualized with the Image J program (Bio-Rad, Richmond, CA, USA). The relative levels were quantified densitometrically by using the Quantity One software (Bio-Rad Laboratories) and calculated according to the reference bands of $\beta$-actin. 


\subsection{Molecular Docking}

The ligands were PF, LIG, SENI, SENA and verapamil .The molecular structure of the ligands was found from NCBI [40] and the SDF file format used for molecular docking was downloaded. The X-ray crystal structure of P-gp (PDB code: 3G60) was retrieved from RCSB Protein Data Bank (4.40 resolution) [41]. This complex structure consists of two homodimeric chains, A and B. Discovery Studio 4.0 (DS) was employed to perform the docking of the compounds into the active sites of P-gp. The protein was prepared by removing crystal water and other hetero atoms, followed by addition of hydrogen, protonation, ionization and energy minimization. The CHARMm force field was applied for geometry optimization. Met68, leu300, tyr303, phe332, leu335, ile336, phe339, gln721, phe724, phe728, leu758, phe833, tyr949, phe974, ser975, val978, ala981, met982, gly985, gln986, and ser989 were amino acid residues of P-gp, and were defined as active sites in the studies [42]. The detailed binding modes of ligands with P-gp were illustrated by docking all the prepared ligands at the defined active site using Libdock, and the Libdock scores were recorded for analysis [43,44].

\section{Conclusions}

In conclusion, PF showed relatively poor absorption in the BBB models. The bidirectional transport of PF across MDCK-MDR1 monolayers was concentration dependent and not saturable. The $\mathrm{B} \rightarrow \mathrm{A} / \mathrm{A} \rightarrow \mathrm{B}$ permeability $E R$ of $\mathrm{PF}$ was more than 2 in the MDCK-MDR1 cells, which indicated that the transport mechanism of PF might be passive diffusion as the dominating process with the active transportation mediated mechanism involved. The increased Papp of $\mathrm{PF}$ in $\mathrm{A} \rightarrow \mathrm{B}$ direction by EDTA-Na 2 suggested that $\mathrm{PF}$ was absorbed via the paracellular route. The $\mathrm{B} \rightarrow \mathrm{A} / \mathrm{A} \rightarrow \mathrm{B}$ permeability $E R$ of $P F$ decreased from 2.210 to 0.690 in the presence of verapamil, which suggested that $P F$ was a substance of P-gp. LIG, SENA and SENI could increase the Papp of PF in A $\rightarrow$ B directions in a concentration-dependent manner. LIG, SENA and SENI behave as effective absorption enhancers in BBB by reducing the expression of P-gp and opening tight junctions. Since there are other proteins to cover the whole functional features of the $\mathrm{BBB}$, there are some limitations of the findings and further experiments about the enhance mechanism of chuanxiong are expected.

Acknowledgments: This work was sponsored by National Natural Science Foundation of China (NO. 81360645), Jiangxi provincial Cultivate Project of Young Scientist (NO. 20122BCB23021), Natural Science foundation of Jiangxi province (20142BAB205088), and Science and Technology Project Funded by Jiangxi Provincial Education Department (NO. GJJ13606).

Author Contributions: Peng-Yi Hu, Qin Zheng, Ming Yang and Qing Wu participated in the research design. Peng-Yi Hu, Dan Liu and Yu Tang performed the experiments and analyzed the data. The manuscript was written by Peng-Yi Hu. All authors read and approved the final manuscript.

Conflicts of Interest: The authors declare no conflict of interest.

\section{References}

1. Ji, Q.; Yang, L.; Zhou, J.; Lin, R.; Zhang, J.; Lin, Q.; Wang, W.; Zhang, K. Protective effects of paeoniflorin against cobalt chloride induced apoptosis of endothelial cells via HIF-1alpha pathway. Toxicol. Vitro 2012, 26, 455-461. [CrossRef] [PubMed]

2. Zhou, H.; Bian, D.; Jiao, X.; Wei, Z.; Zhang, H.; Xia, Y.; He, Y.; Dai, Y. Paeoniflorin protects against lipopolysaccharide-induced acute lung injury in mice by alleviating inflammatory cell infiltration and microvascular permeability. Inflamm. Res. 2011, 60, 981-990. [CrossRef] [PubMed]

3. Hu, Z.Y.; Xu, L.; Yan, R.; Huang, Y.; Liu, G.; Zhou, W.X.; Zhang, Y.X. Advance in studies on effect of paeoniflorin on nervous system. China J. Chin. Mater. Med. 2013, 38, 297-301.

4. Zhong, S.Z.; Ge, Q.H.; Li, Q.; Qu, R.; Ma, S.P. Peoniflorin attenuates A $\beta$ (1-42)-mediated neurotoxicity by regulating calcium homeostasis and ameliorating oxidative stress in hippocampus of rats. J. Neurol. Sci. 2009, 280, 71-78. [CrossRef] [PubMed] 
5. Liu, D.Z.; Zhu, J.; Jin, D.Z.; Zhang, L.M.; Ji, X.Q. Behavioral recovery following subchronic paeoniflorin administration in the striatal6-OHDA lesion rodent model of Parkinson's disease. J. Ethnopharmacol. 2007, 112, 327-332. [CrossRef] [PubMed]

6. Yang, X.W.; Guo, J.; Xu, W. Absorption and transport characteristic of paeoniflorin and its derivatives in model of Caco-2 cell monolayers. Chin. Tradit. Herbal Drugs 2013, 45, 2097-2104.

7. Wu, J.; Yao, N.; Wang, D.W. Determination of paeoniflorin in rat plasma by HPLC-MS/MS and its pharmacokinetics. China J. Chin. Mater. Med. 2008, 33, 2369-2373.

8. Lai, L.L.; Fan, H.J.; Zhang, Y.Y.; Yang, J.H.; Wang, H.T. Analysis of compatibility regularity of ligustrazine. Chin. Arch. Tradit. Chin. Med. 2015, 33, 2335-2337.

9. Su, Z.T.; Xu, J.L.; Liu, Y.; Yang, S.; Yang, M. The study on promotion of absorption and synergistic effect of Chuanxiong Rhizoma with helicid. Chin. J. Exp. Tradit. Med. Formulae 2012, 18, 176-178.

10. Wang, Q.; Shen, L.; Liang, S.; Ma, S.Y.; Feng, Y.; Ruan, K.F. Effects of Ligusticum chuanxiong on plasma and brain pharmacokinetics of active ingredients from Gastrodia elata in migraine rats. Chin. Tradit. Pat. Med. 2015, 37, 62-69.

11. Zhen, Q.; Liu, J.Y.; Fu, S.L.; Liu, Y.J.; Qian, J.; Yang, M. Effects of chuanxiong rhizoma on brain pharmacokinetics of gastrodigenin in rats. Chin. J. New Drugs Clin. Rem. 2012, 31, 263-266.

12. Wang, P.; Wang, C.; Lou, Y.C. Borneol and Rhizome of Chuanxiong on facilitating permeation for compound shuyu jiangnao decoction through blood brain barrier. J. Hubei Univ. Chin. Med. 2011, 13, 21-23.

13. Ren, C.; Wang, B.; Li, N.; Jin, K.; Ji, X. Herbal formula Danggui-Shaoyao-San promotes neurogenesis and angiogenesis in rat following middle cerebral artery occlusion. Aging Dis. 2015, 6, 245-253. [CrossRef] [PubMed]

14. Liu, G.; Hu, Z.Y.; Wang, T.; Yang, S.; Zhou, W.X.; Zhang, Y.X. Preliminary study of Danggui Shaoyao San active ingredient paeoniflorinresisting nerve inflammatory reaction. Chin. J. Pharmacol. Toxicol. 2011, $25,94$.

15. Mu, Q.; Liu, P.; Hu, X.; Gao, H.; Zheng, X.; Huang, H. Neuroprotective effects of Buyang Huanwu decoction on cerebral ischemia-induced neuronal damage. Neural Regen. Res. 2014, 9, 1621-1627. [PubMed]

16. Li, Q.Y.; Gan, G.P.; Liu, Y.W. The chemical composition and pharmacological research progress of rhizoma Ligusticum chuanxiong. Lishizhen Med. Mater. Med. Res. 2006, 17, 1298-1299.

17. Wang, H.J.; Zhang, L.C.; Zhang, Y.J.; Gu, W.Y.; Wu, Z.H.; Hu, J.H. Mechanism of enhancing effect of essential oils from Ligusticum chuanxiong Hort. through rabbit skin by increased skin blood flow. Chin. Pharm. J. 2010, 45, 1925-1929.

18. Sheng, Y.M.; Meng, X.L.; Chun, Y.; Wang, Z.; Zhang, Y. Effects of aetherolea from chuanxiong on ischemical reperfusion injury in rats and the survival of cerebral cortex neurons in vitro. Lishizhen Med. Mater. Med. Res. 2012, 23, 536-538.

19. Wang, J.; Du, J.R.; Wang, Y.; Wan, F.C. Z-ligustilide attenuates lipopolysaccharide-induced proinfammatory response via inhibiting TNF-кB pathway in primary rat microglia. Acta Pharmacol. Sin. 2010, 31, 791-797. [CrossRef] [PubMed]

20. Chan, S.K.; Cheng, T.Y.; Lin, G. Relaxation effects of ligustilide and senkyunolide A, two main constituents of Ligusticum chuanxiong, in rat isolated aorta. J. Ethnopharmacol. 2007, 111, 677-680. [CrossRef] [PubMed]

21. Wang, Y.H.; Liang, S.; Xu, D.S.; Lin, X.; He, C.Y.; Feng, Y.; Hong, Y.L. Effect and mechanism of senkyunolideI as an anti-migraine compound from Liguchuanxiong. J. Pharm. Pharmacol. 2011, 63, 261-266. [CrossRef] [PubMed]

22. Zuo, A.H.; Cheng, M.C.; Wang, L.; Xiao, H.B. Analysis of chemical constituents of Chuanxiong Rhizoma absorbed into rat brain tissues by UPLC-Q-TOF-MS. China J. Chin. Mater. Med. 2012, 37, 3647-3650.

23. Ueda, K. ABC proteins protect the human body and maintain optimal health. Biosci. Biotechnol. Biochem. 2011, 75, 401-409. [CrossRef] [PubMed]

24. Shityakov, S.; Forster, C. In silico structure-based screening of versatile P-glycoprotein inhibitors using polynomial empirical scoring functions. Adv. Appl. Bioinform. Chem. 2014, 7, 1-9. [CrossRef] [PubMed]

25. Wang, Q.; Rager, J.D.; Weinstein, K.; Kardos, P.S.; Dobson, G.L.; Li, J.; Hidalgo, I.J. Evaluation of the MDR-MDCK cell line as a permeability screen for the blood-brain barrier. Int. J. Pharm. 2005, 288, 349-359. [CrossRef] [PubMed]

26. Navarroa, C.; Gonzalez-Alvarez, I.; Gonzalez-Alvarez, M. Influence of polyunsaturated fatty acids on cortisol transport through MDCK and MDCK-MDR1 cells as blood-brain barrier in vitro model. Eur. J. Pharm. Sci. 2011, 42, 290-299. [CrossRef] [PubMed] 
27. Hong, L.; Xu, C.; O’Neal, S.; Bi, H.C.; Huang, M.; Zheng, W.; Zeng, S. Roles of P-glycoprotein andmultidrugresistance protein in transporting para-aminosalicylic acid and its $N$-acetylated metabolite in mice brain. Acta Pharmacol. Sin. 2014, 35, 1577-1585. [CrossRef] [PubMed]

28. Hellinger, E.; Veszelka, S.; Tóth, A.E.; Walter, F.; Kittel, A.; Bakk, M.L.; Tihanyi, K.; Háda, V.; Nakagawa, S.; Duy, T.D.; et al. Comparison of brain capillary endothelial cell-based and epithelial (MDCK-MDR1, Caco-2, and VB-Caco-2) cell-based surrogate blood-brain barrier penetration models. Eur. J. Pharm. Biopharm. 2012, 82, 340-351. [CrossRef] [PubMed]

29. Li, H.; Jin, H.E.; Kim, W.; Han, Y.H.; Kim, D.D.; Chung, S.J.; Shim, C.K. Involvementof P-glycoprotein, multidrug resistance protein 2 and breast cancer resistanceprotein in the transport of belotecan and topotecan in Caco-2 and MDCKII cells. Pharm. Res. 2008, 25, 2601-2612. [CrossRef] [PubMed]

30. Chen, Y.; Wang, J.Y.; Xin, R.; Tan, X.B. Impact of saikosaponin on absorption and transport of paeoniflorin in Caco-2 cell model. China J. Chin. Mater. Med. 2012, 37, 1850-1854.

31. Liang, X.L.; Zhao, L.J.; Liao, Z.G.; Zhao, G.W.; Zhang, J.; Chao, Y.C.; Yang, M.; Yin, R.L. Transport properties of puerarin and effect of Radix Angelicae Dahuricae extract on the transport of puerarin in Caco-2 cell model. J. Ethnopharmacol. 2012, 144, 677-682. [CrossRef] [PubMed]

32. Demirbas, S.; Stavchansky, S. Effects of citicholine and dimethylsulfoxide on transepithelialtransport of passively diffused drugs in the Caco-2 cell culturemodel. Int. J. Pharm. 2003, 251, 107-112. [CrossRef]

33. Fan, X.; Chai, L.J.; Zhang, H.; Wang, Y.F.; Zhang, B.L.; Gao, X.M. Borneol depresses P-glycoprotein function by a NF-кB signaling mediated mechanism in a Blood Brain Barrier in vitro model. Int. J. Mol. Sci. 2015, 16, 27576-27588. [CrossRef] [PubMed]

34. Sarvagalla, S.; Singh, V.K.; Ke, Y.Y.; Shiao, H.Y.; Lin, W.H.; Hsu, T.A.; Coumar, M.S. Identification of ligand efficient, fragment-like hits from an HTS library: Structure-based virtual screening and docking investigations of $2 \mathrm{H}$ - and $3 \mathrm{H}$-pyrazolo tautomers for Aurora kinase A selectivity. J. Comput. Aided Mol. Des. 2015, 29, 89-100. [CrossRef] [PubMed]

35. Usha, T.; Middha, S.K.; Goyal, A.K.; Karthik, M.; Manoj, D.; Faizan, S.; Goyal, P.; Prashanth, H.; Pandeb, V. Molecular docking studies of anti-cancerous candidates in Hippophae rhamnoides and Hippophae salicifolia. J. Biomed. Res. 2014, 28, 406-415. [PubMed]

36. Shityakov, S.; Neuhaus, W.; Dandekar, T.; Forster, C. Analysing molecular polar surface descriptors to predict blood-brain barrier permeation. Int. J. Comput. Biol. Drug Des. 2013, 6, 146-156. [CrossRef] [PubMed]

37. Portnoy, E.; Gurina, M.; Magdassi, S.; Eyal, S. Evaluation of the near infrared compound Indocyanine Green as a probe substrate of P-glycoprotein. Mol. Pharm. 2012, 12, 3595-3601. [CrossRef] [PubMed]

38. Vadlapudi, A.D.; Vadlapatla, R.K.; Kwatra, D.; Earla, R.; Samanta, S.K.; Pal, D.; Mitra, A.K. Targeted lipid based drug conjugates: A novel strategy for drug delivery. Int. J. Pharm. 2012, 434, 315-324. [CrossRef] [PubMed]

39. Liang, X.L.; Zhao, L.J.; Liao, Z.G.; Yin, R.L.; Zhao, G.W.; Cao, Y.C. Effects of radix angelicae dahuricae extract on p-glycoprotein activity in Caco-2 cells. Chin. Hosp. Pharm. J. 2012, 32, 1781-1785.

40. The Molecular Structure of the Ligands was Found from NCBI. Available online: http://www.ncbi.nlm. nih.gov/pubmed (accessed on 31 July 2015).

41. Mei, M.; Zhang, Y.; Ren, J.H.; Xie, D.; Jia, Y.F.; Hu, J.P.; Li, Y.; Dai, J.G.; Chen, X.G. Resistance reversal effect of a novel taxane compound NPB304 and its collaboration with verapamil. Acta Pharm. Sin. 2014, 49, 1279-1288.

42. Aller, S.G.; Yu, J.; Ward, A.; Weng, Y.; Chittaboina, S.; Zhuo, R.P.; Harrell, P.M.; Trinh, Y.T.; Zhang, Q.H.; Urbatsch, I.L.; et al. Structure of p-glycoprotein reveals a molecular basis for poly-specific drug binding. Science 2009, 323, 1718-1722. [CrossRef] [PubMed]

43. Shityakov, S.; Forster, C. Multidrug resistance protein P-gp interaction with nanoparticles (fullerenes and carbon nanotube) to assess their drug delivery potential: A theoretical molecular docking study. Int. J. Comput. Biol. Drug Des. 2013, 6, 343-357. [CrossRef] [PubMed]

44. Shityakov, S.; Forster, C. In silico predictive model to determine vector-mediated transport properties for the blood-brain barrier choline transporter. Adv. Appl. Bioinform. Chem. 2014, 7, 23-36. [CrossRef] [PubMed]

Sample Availability: Not Available.

(C) 2016 by the authors; licensee MDPI, Basel, Switzerland. This article is an open access article distributed under the terms and conditions of the Creative Commons by Attribution (CC-BY) license (http:/ / creativecommons.org/licenses/by/4.0/). 